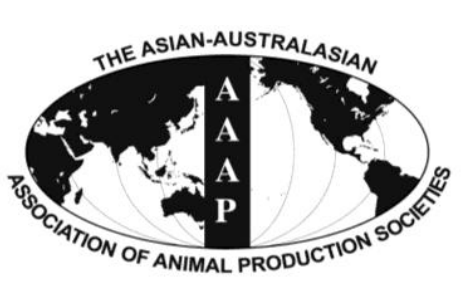

Open Access

Asian Australas. J. Anim. Sci.

Vol. 28, No. 3 : 451-455 March 2015

http://dx.doi.org/10.5713/ajas.14.0259

www.ajas.info

pISSN 1011-2367 elSSN 1976-5517

\title{
A Review of Recent Developments in Buffalo Reproduction - A Review
}

\author{
H. M. Warriach ${ }^{1,2, *}$, D. M. McGill' ${ }^{2}$, R. D. Bush ${ }^{3}$, P. C. $\mathrm{Wynn}^{2}$, and K. R. Chohan ${ }^{4}$ \\ ${ }^{1}$ University of Veterinary and Animal Sciences, Lahore 54000, Pakistan
}

\begin{abstract}
The buffalo is an important livestock resource in several countries of South Asia and the Mediterranean regions. However, reproductive efficiency is compromised due to known problems of biological and management origins, such as lack of animal selection and poor nutrition. Under optimal conditions puberty is attained at 15 to 18 months in river buffalo, 21 to 24 months in swamp buffalo and is influenced by genotype, nutrition, management and climate. However, under field conditions these values deteriorate up to a significant extant. To improve reproductive efficiency, several protocols of oestrus and ovulation synchronization have been adopted from their use in commercial cattle production. These protocols yield encouraging pregnancy rates of (30\% to 50\%), which are comparable to those achieved in buffaloes bred at natural oestrus. The use of sexed semen in buffalo heifers also showed promising pregnancy rates $(50 \%)$ when compared with conventional non-sexed semen. Assisted reproductive technologies have been transferred and adapted to buffalo but the efficiency of these technologies are low. However, these latest technologies offer the opportunity to accelerate the genetic gain in the buffalo industry after improving the technology and reducing its cost. Most buffaloes are kept under the small holder farming system in developing countries. Hence, future research should focus on simple, adoptable and impact- oriented approaches which identify the factors determining low fertility and oestrus behaviour in this species. Furthermore, role of kisspeptin needs to be explored in buffalo. (Key Words: Buffaloes, Reproduction, Developments, Techniques)
\end{abstract}

\section{INTRODUCTION}

Buffalo has a significant role in the agricultural economy of many developing countries by providing milk, meat and draught power. The world population of buffalo is estimated to be 199 million (FAOSTAT, 2012) with more than $96 \%$ of the population located in Asia including $16.4 \%$ of Pakistan's contribution. In recent decades, buffalo farming has expanded widely in the Mediterranean and Latin America as well as, in Central/Northern Europe where several herds were introduced.

Dairy buffaloes have been used for milk production in

\footnotetext{
* Corresponding Author: H. M. Warriach. Tel: +92-3334315107, Fax: +92-429211461, E-mail: hassanwarriach71@yahoo.com

${ }^{2}$ EH Graham Centre for Agricultural Innovation, Charles Sturt University, 2650 NSW, Australia.

${ }^{3}$ Faculty of Veterinary Science, University of Sydney, Camden NSW 2570, Australia.

4 Department of Pathology and Obstetrics and Gynecology, Upstate Medical University Syracuse, New York, 13210, USA. Submitted Apr. 8, 2014; Revised Jul. 3, 2014; Accepted Aug. 28, 2014
}

India, Pakistan, some other South Asian countries, the Middle East and Italy; while dairy characteristics are being induced in the local population of Indo-Chinese Region and South America through crossbreeding with Pakistani Nili Ravi and Indian Murrah buffaloes. The milk yield increased from 700 to $2,000 \mathrm{~kg} /$ year in China through crossbreeding (Yang et al., 2007).

The buffalos can utilize poorer quality roughages, adapt to harsher environments and are more resistant to several bovine tropical diseases. Despite these merits, buffalo have relatively poor reproductive efficiency irrespective of their location throughout the world. Buffalo exhibit many of the known reproductive disorders including delayed onset of puberty, poor oestrus expression, longer postpartum ovarian quiescence, and most importantly lowered conception rates particularly when bred artificially (Gordon, 1996). However, higher fertility could be achieved through better feeding and management (Perera et al., 1987; Usmani et al., 1990; Qureshi et al., 2007). It appears that because buffalo are located mostly in developing countries with meager resources, there is limited quality research in the area of 
basic physiology, health, management, nutrition and applied reproduction.

The objective of this review is to examine the major recent developments in buffalo reproduction. We discuss the impact of the various techniques as well as bottlenecks and possible future developments which will lead to improve reproductive performance in this species.

\section{PUBERTY}

Buffalo usually attain puberty when they reach about $60 \%$ of their adult body weight (250 to 400 ) $\mathrm{kg}$, but the age at which they attain puberty can be highly variable, ranging from 18 to 46 months (Jainudeen and Hafez, 1993). The factors that influence this are genotype, nutrition, management and climate. It could be attained under optimized conditions at 15 to 18 months in river buffalo and 21 to 24 months in swamp buffalo (Borghese, 2005). The delay in puberty, consequently delays conception and results in low reproductive efficiency and lengthening of the non-productive life. A major cause of delayed puberty may be poor feeding and management under field conditions.

\section{OESTROUS CYCLE}

In order to enhance reproductive efficiency of buffalo, a thorough understanding of the regulatory mechanisms involved in the oestrus cycle is required. The duration of the oestrous cycle in buffalo is similar to that in cattle, ranging from 17 to 26 days with a mean of around 21 days (Jainudeen and Hafez, 1993). However, there is a greater variability of the oestrous cycle length in buffalo compared to cattle, with a greater incidence of both abnormally short and long oestrous cycles. This may be attributed to various factors including adverse environmental conditions, nutrition and irregularities in secretion of ovarian steroid hormones (Kaur and Arora, 1982; Nanda et al., 2003).

In buffaloes, ovarian follicular dynamics during the oestrous cycle is similar to that in cattle. Studies from India (Taneja et al., 1996), Brazil (Baruselli et al., 1997) and Pakistan (Warriach and Ahmad, 2007; Figure 1) have shown clearly that the majority of buffalo have two waves of follicular activity during their oestrous cycle. More investigations on the effect of follicle stimulating hormone and nutrition on number of follicular waves need to be studied in buffaloes.

Studies on oestrous behavior and endocrinology in buffalo (Roy and Prakash, 2009; Singh et al., 2000) indicate considerable variations in reproductive endocrine activity without external signs of oestrus (silent heat) are common. The low intensity of oestrus in buffaloes may be due to low circulating concentrations of 17- $\beta$ oestradiol in comparison with dairy cattle (Seren et al., 1995).
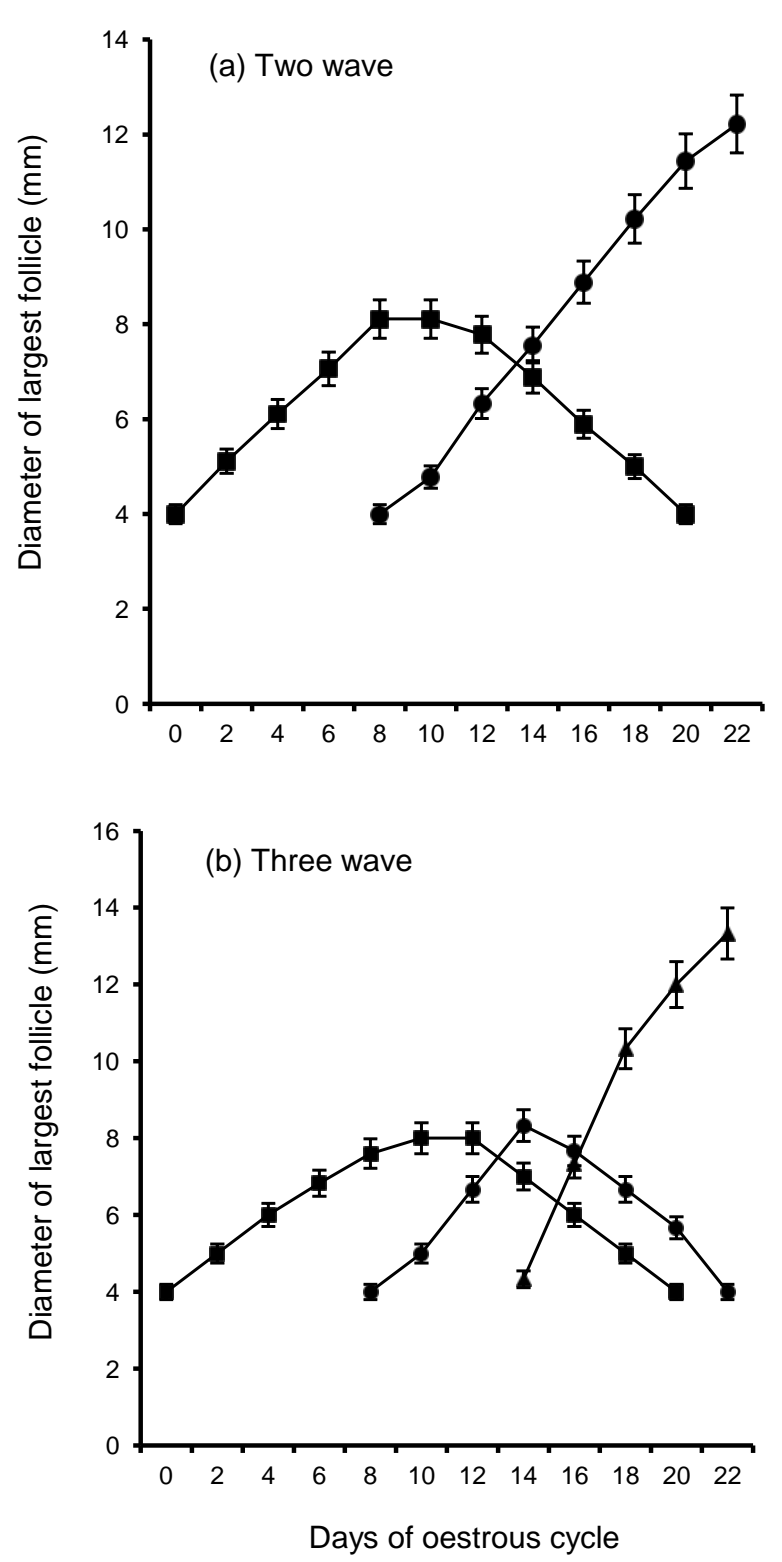

Figure 1. Observed patterns of development for the largest follicle during oestrous cycles. Shown are the average diameters of the first $(\boldsymbol{\square}-\mathbf{\square})$, second $(\bullet-\bullet)$ and third $(\boldsymbol{\Delta}-\mathbf{\Delta})$ sequentially largest follicles in buffaloes that had (a) two $(n=9)$ or (b) three $(n$ =3) waves of follicular development respectively (Warriach and Ahmad, 2007).

Furthermore, tying up the animals as per normal husbandry practices in many developing countries restricts the ability of buffalo farmers to observe heat signs (Warriach et al., 2009). Buffalos also tend to show heat signs during the night when farmers are not observing their animals (Unpublished data). Season is another extrinsic factors that influences the characteristics of oestrous behaviour. In the tropics, high ambient temperature reduces sexual activity during the day (Jainudeen, 1977) and shortens the oestrous period (Gill et al., 1973) with the 
incidence of silent oestrous more common during the hot summer season. These adverse effects of heat stress make oestrous detection much more difficult in buffalo. Oestrous detection could be significantly improved through the introduction of a teaser bull or an androgenzied female (Chohan et al., 1992).

The interval between standing oestrous and ovulation, which is very important for artificial insemination, was 30 hours in buffaloes (Warriach et al., 2008). Under field conditions, the am-pm rule of insemination originally developed for cattle (Trimberger, 1948) is generally followed in buffaloes. To follow this rule, the buffaloes should be bred $12 \mathrm{~h}$ after the detection of standing oestrus. However, onset of heat signs instead of onset of standing oestrus has been erroneously considered as the land mark with buffaloes often being inseminated, earlier than required. This early breeding is potentially responsible for lowered fertility, and can be explained by the fact, there is an interval of about 8 to $10 \mathrm{~h}$ between onset of heat signs and onset of standing oestrus. This indicates buffaloes should be inseminated $12 \mathrm{~h}$ after the detection of standing oestrus (detection by bull/teaser) or alternatively 18 to $24 \mathrm{~h}$ after the onset of heat signs. In order to confirm this approach, investigations are required on the timing of insemination in relation to standing oestrus and pregnancy rate.

\section{SYNCHRONIZATION OF OESTROUS CYCLE}

Various studies using protocols for synchronization based on progesterone and gonadotropin releasing hormone (GnRH) administration together with prostaglandin to induce luteolysis during breeding season have yielded quite promising conception rates ranging from $30 \%$ to $50 \%$ (Table 1). However, some buffaloes do not respond to treatment, especially during the low breeding season. There could be several reasons for this, but among the most likely is the animal's follicular status at the beginning of treatment. The ideal time of treatment can be established by determining ovarian activity by ultrasound (De Rensis and López-Gatius, 2007). The presence of the dominant follicle and an active corpus luteum (CL) indicate the success of

Table 1. Fertility rates after various synchronization methods in buffaloes as reported in the literature

\begin{tabular}{llc}
\hline Reference & Treatment & $\begin{array}{c}\text { Pregnancy } \\
\text { rates }(\%)\end{array}$ \\
\hline Warriach et al., 2008 & GnRH+PGF2 $\alpha+$ GnRH & 36 \\
Naseer et al., 2011 & CIDR & 37 \\
Paul and Prakash, 2005 & GnRH+PGF2 $\alpha+$ GnRH & 33 \\
Berber et al., 2002 & GnRH+PGF2 $\alpha+$ GnRH & 56.5 \\
Neglia et al., 2003 & GnRH+PGF2 $\alpha+$ GnRH & 36 \\
Chohan, 1998 & PGF2 $\alpha$ (cloprostenol) & 53 \\
Rao and Rao, 1983 & PRID & 41 \\
\hline
\end{tabular}

synchronization. Protocols for buffaloes with limited follicular and luteal activity, remain to be refined, but they most likely will be devised around the strategic timing of administration of reagents currently used in synchronization protocols while ensuring that the supply of dietary energy and protein are not lacking.

\section{SEXED FROZEN SEMEN}

Semen sexing has been successfully used for producing living offspring in bovine species (Seidel et al., 1999). In buffalo, a difference in DNA content between $\mathrm{X}$ and $\mathrm{Y}$ sperm was found, and based on this difference it has been further demonstrated that processing buffalo semen was feasible ( $\mathrm{Lu}$ et al., 2007). In a recent study, promising pregnancy rates $(50 \%)$ were achieved when inseminating a dose of sexed semen containing 4 million spermatozoa (Gaviraghi et al., 2013). In order to expand use of this technology, there is a need to further refine this protocol for buffalo breeds of commercial significance such as the NiliRavi buffalo of Pakistan.

\section{ASSISTED REPRODUCTIVE TECHNOLOGIES}

The first successful embryo transfer in buffalo was performed in the United States of America (Drost et al., 1983). Subsequent successful transfers have been reported from many other countries. However, the success rate is much lower in buffaloes, due to their inherently low fertility and poor superovulatory response (Misra et al., 1990). The average yield of transferable embryos is less than one per superovulated donor. The buffalo ovary has a smaller population of recruitable follicles at any given time; an average of 12,000 primary follicles has been reported (Danell, 1987), compared to the average in the ovary of the cow, which has an average of 133,000 (Erickson, 1966). This technique comprises a series of carefully integrated sequential steps including donor selection, donor treatment, recipient selection, insemination of the donor, embryo recovery, embryo handling and evaluation, embryo transfer, and recipient care. The technology has to be refined to account for the lower, less responsive follicle population in the buffalo.

Assisted reproductive technologies have been introduced to overcome the inherent reproductive problems, fast propagation of superior germplasm, and to reduce the generation intervals. These technologies provide an excellent source of embryos for carrying on basic research in developmental physiology, farm animal breeding, and for commercial application of the emerging bio techniques like cloning and transgenesis. During the past two decades, considerable advances have been made in our understanding of buffalo reproductive physiology, however, previous reviews (Palta and Chauhan, 1998; Gasparrini, 
2002) and more recent studies suggest that the rate of transferable embryo yield remains at a plateau (Manjunatha et al., 2009). Results have been quite variable between laboratories and are most likely related to differences in embryo physiology, metabolism, and culture requirements among buffalo breeds. Further studies are also needed to improve the cryopreservation of in vitro embryo production embryos.

\section{FUTURE RESEARCH}

The hypothalamo-pituitary-gonadal axis is the regulatory system for reproduction in mammals. A newly discovered neural peptide, kisspeptin, has opened a new era in reproductive neuroendocrinology. As shown in a variety of mammals, kisspeptin is a potent endogenous secretagogue of GnRH, and the kisspeptin neuronal system governs both the pulsatile GnRH secretion that drives folliculogenesis, spermatogenesis and steroidogenesis, and the GnRH surge that triggers ovulation in females (Okamura et al., 2013). Role of kisspeptin needs to be explored in buffalo.

\section{CONCLUSIONS}

Buffaloes are an important livestock resource for many countries. Most buffaloes are kept under the small holder farming system in developing countries. Future research should focus on simple, adoptable and impact oriented approaches which identify the factors limiting fertility and oestrus behaviour in this commercially significant species.

Despite the inherited problems in buffalo slow progress has been made in the application of assisted reproductive techniques. Artificial insemination is practiced commercially; embryo transfer, in vitro embryo production, and nucleus transfer remain in the realm of experimentation. If their costs are reduced these latest techniques offer the opportunity to accelerate the genetic gain in the buffalo industry with the proviso that they are used in conjunction with efficient national progeny testing and sire evaluation programs.

\section{ACKNOWLEDGMENTS}

This paper was presented at first the joint International Symposium on the Nutrition of Herbivores/ International Symposium on Ruminant Physiology (ISNH/ISRP) in Canberra, Australia, (September 8-12th, 2014).

\section{REFERENCES}

Baruselli, P. S., R. G. Mucciolo, J. A. Visintin, W. G. Viana, R. P. Arruda, and E. H. Madureira, C. A. Oliveira, and J. R. Molero-
Filho. 1997. Ovarian follicular dynamics during the estrous cycle in buffalo (Bubalus bubalis). Theriogenology 47:15311547.

Berber, R. C. A., E. H. Madureira, and P. S. Baruselli. 2002. Comparison of two ovsynch protocols (GnRH vs. LH) for fixed timed insemination in buffalo (Bubalus bubalis). Theriogenology 57:1421-1430.

Borghese, A. 2005. In: Technical Series 67. Food and Agriculture Organization, Rome, Italy.

Chohan, K. R., R. A. Chaudhry, J. Iqbal, and T. Rahil. 1992. Comparative efficiency of male and androgenized female teaser for oestrus detection in buffaloes. J. Appl. Anim. Res. 2:23-26.

Chohan, K. R. 1998. Estrus synchronization with lower doses of PGF2 $\alpha$ and subsequent fertility in subestrous buffalo. Theriogenology 50:1101-1108.

Danell, B. 1987. Oestrous Behavior, Ovarian Morphology and Cyclical Variation in Follicular System and Endocrine Pattern in Water Buffalo Heifers. PhD Thesis: Sveriges Lantbruks universitet, Uppsala, Sweden. pp. 54-94.

De Rensis, F. and F. López-Gatius. 2007. Protocols for synchronizing estrus and ovulation in buffalo (Bubalus bubalis): A review. Theriogenology 67:209-216.

Drost, M., Jr. J. M. Wright, W. S. Cripe, and A. R. Richter. 1983. Embryo transfer in water buffalo (Bubalus bubalis). Theriogenology 20:579-84.

Erickson, B. H. 1966. Development and senescence of the postnatal bovine ovary. J. Anim. Sci. 25:800-805.

Gasparrini, B. 2002. In vitro embryo production in buffalo species: state of the art. Theriogenology 57:237-256.

Gaviraghi, A., R. Puglisi, D. Balduzzi, A. Severgnini, V. Bornaghi, G. Bongioni, A. Frana, L. M. Gandini, A. Lukaj, C. Bonacina, and A. Galli. 2013. Minimum number of spermatozoa per dose in Mediterranean Italian buffalo (Bubalus bubalis) using sexed frozen semen and conventional artificial insemination. Theriogenology 79:1171-1176.

Gill, R. S., P. C. Gangwar, and D. S. Kooner. 1973. Studies on oestrous behaviour of buffaloes. Indian J. Anim. Sci. 43:472475.

Gordon, I. 1996. Controlled reproduction in cattle and buffaloes. CABI, Wallingford, UK. vol. 1. pp. 452.

Jainudeen, M. R. 1977. Reproduction of Malaysian swamp buffalo (Bubalus bubalis). Proceeding of Ist Joint Conference on Health and production Australian and Local Cattle in South East Asia, Ministry of Agriculture, Malaysia, Bull. No. 146, pp. 162-169.

Jainudeen, M. R. and E. S. E. Hafez. 1993. Cattle and buffalo. In: Reproduction in Farm Animals (Ed. E. S. E. Hafez), 6th ed. Lea and Febiger, Philadelphia, PA, USA. pp. 315-329.

Kaur, H. and S. P. Arora. 1982. Influence of level of nutrition and season on the oestrous cycle rhythm and on fertility in buffaloes. Trop. Agric. (Trinidad) 59:274-278.

Lu, Y. Q., X. W. Liang, M. Zhang, W. L. Wang, Y. Kitiyanant, S. S Lu, B. Meng, and K. H. Lu. 2007. Birth of twins after in vitro fertilization with flow-cytometric sorted buffalo (Bubalus bubalis) sperm. Anim. Reprod. Sci. 100:192-196.

Manjunatha, B. M., J. P. Ravindra, P. S. P. Gupta, M. Devaraj, and S. Nandi. 2009. Effect of breeding season on in vivo oocyte recovery and embryo production in non-descriptive Indian 
river buffaloes (Bubalus bubalis). Anim. Reprod. Sci. 111: 376-383.

Misra, A. K., B. V. Joshi, P. L. Agrawala, R. Kasiraj, S. Sivaiah, N. S. Rangareddi, and M. U. Siddiqui. 1990. Multiple ovulation and embryo transfer in Indian buffalo (Bubalus bubalis). Theriogenology 33:1131-1141.

Nanda, A. S., P. S. Brar, and S. Prabhakar. 2003. Enhancing reproductive performance in dairy buffalo: major constraints and achievements. Reproduction 61 (Suppl.):27-36.

Naseer, Z., E. Ahmad, J. Singh, and N. Ahmad. 2001. Fertility following CIDR based synchronization regimens in anoestrous Nili-Ravi buffaloes. Reprod. Domest. Anim. 46:814-817.

Neglia, G., B. Gasparrini, R. Di Palo, C. De Rosa, L. Zicarelli, and G. Campanile. 2003. Comparison of pregnancy rates with two estrus synchronization protocols in Italian Mediterranean Buffalo cows. Theriogenology 60:125-133.

Okamura, H., T. Yamamura, and Y. Wakabayashi. 2013. Kisspeptin as a master player in the central control of reproduction in mammals: An overview of kisspeptin research in domestic animals. Anim. Sci. J. 84:369-381.

Palta, P. and M. S. Chauhan. 1998. Laboratory production of buffalo (Bubalus bubalis) embryos. Reprod. Fertil. Dev. 10: 379-392.

Paul, V. and B. S. Prakash. 2005. Efficacy of the ovsynch protocol for synchronization of ovulation and fixed-time artificial insemination in Murrah buffaloes (Bubalus bubalis). Theriogenology 64:1049-1060.

Perera, B. M. A. O. 1987. A review of experiences with oestrous synchronization in buffaloes in Sri Lanka. Buff. J. 1(Suppl.):105-114.

Qureshi, M. S., S. Khan, and N. Ahmad. 2007. Pregnancy depresses milk yield in dairy buffaloes. Italian J. Anim. Sci. 6: (Suppl. 2):1290-1293.

Rao, A. R. and C. Rao Ch. 1983. Synchronization of oestrus and fertility in buffaloes with a progesterone releasing intravaginal device. Vet. Rec. 113:623-624.
Roy, K. S. and B. S. Prakash. 2009. Plasma progesterone, oestradiol-17 $\beta$ and total oestrogen profiles in relation to oestrous behaviour during induced ovulation in Murrah buffalo heifers. J. Anim. Physiol. Anim. Nutr. 93:486-495.

Seidel, Jr. G. E., J. L. Schenk, L. A. Herickoff, S. P. Doyle, Z. Brink, R. D. Green, and D. G. Cran. 1999. Insemination of heifers with sexed sperm. Theriogenology 52:1407-1420.

Seren, E., A. Parmeggiani, and G. Campanile. 1995. The control of ovulation in Italian buffalo. In: Proc. of the Symposium Reproduction and Animal Breeding: Advances and Strategy, Milan, Italy. pp. 265-275.

Singh, J., A. S. Nanda, and G. P. Adams. 2000. The reproductive pattern and efficiency of female buffaloes. Anim. Reprod. Sci. 60-61:593-604.

Taneja, M., A. Ali, and G. Singh. 1996. Ovarian follicular dynamics in water buffalo. Theriogenology 46:121-130.

Trimberger, G. W. 1948. Breeding Efficiency in Dairy Cattle from Artificial Insemination at Various Intervals before and after Ovulation. Nebraska Agriculture Experimental Station. 153:1.

Usmani, R. H., R. A. Dailey, and E. K. Inskeep. 1990. Effects of limited suckling and varying prepartum nutrition on postpartum reproductive traits of milked buffaloes. J. Dairy Sci. 73:1564-1570.

Yang, B., X. L. Q. Zeng, J. Qin, and C. Yang. 2007. Dairy buffalo breeding in countryside of China. Italian J. Anim. Sci. 6: (Suppl. 2):25-29.

Warriach, H. M. and N. Ahmad. 2007. Follicular waves during the oestrous cycle in Nili-Ravi buffaloes undergoing spontaneous and PGF2alpha-induced luteolysis. Anim. Reprod. Sci. 101: 332-337.

Warriach, H. M., D. McGill, R. D. Bush, and P. C. Wynn. 2012. Production and reproductive performance of Nili-Ravi buffalo under field conditions of Pakistan. J. Anim. Plant Sci. (Suppl. 3):121-124.

Warriach, H. M., A. A. Channa, and N. Ahmad. 2008. Effect of oestrus synchronization methods on oestrus behaviour, timing of ovulation and pregnancy rate during the breeding and low breeding seasons in Nili-Ravi buffaloes. Anim. Reprod. Sci. 107:62-67. 